\title{
A RARE CASE OF SHPRINTZEN GOLDBERG SYNDROME
}

\author{
S. Y. Ingle ${ }^{1}$ Prashant Shah ${ }^{2}$, Priyanka Karande 3
}

${ }^{1}$ Associate Professor, Department of Paediatrics, Krishna Institute of Medical College and Hospital, Karad. ${ }^{2}$ Assistant Professor, Department of Paediatrics, Krishna Institute of Medical College and Hospital, Karad. ${ }^{3}$ Resident, Department of Paediatrics, Krishna Institute of Medical College and Hospital, Karad.

\begin{abstract}
The Shprintzen-Goldberg syndrome is very rare with fewer than fifty cases described in the medical literature to date. Here, we present a 12-year male child with craniosynostosis along with Marfanoid features with skeletal and neurological abnormalities. It is a multiple anomaly syndrome that affects many parts of the body.
\end{abstract}

\section{KEYWORDS}

Shprintzen-Goldberg Syndrome, Craniosynostosis, Marfanoid Habitus.

HOW TO CITE THIS ARTICLE: Ingle SY, Shah P, Karande P. A rare case of shprintzen goldberg syndrome. J. Evolution Med. Dent. Sci. 2016;5(18):914-916, DOI: $10.14260 /$ jemds/2016/212

\section{INTRODUCTION}

Shprintzen-Goldberg syndrome is one of a group of disorders that affects many parts of the body. Affected individuals have combination of distinctive facial features and skeletal and neurological abnormalities. The aim of this case report was to present a case of Shprintzen-Goldberg syndrome and describe in detail.

\section{CASE REPORT}

A 12-year male child presented with complaints of cold, cough since 3 days along with fever of two days, breathlessness since morning. On further examination revealed salient features of craniosynostosis, multiple skeletal abnormalities and features of Marfan syndrome.

Past history revealed a 32 weeks preterm male child (G 2, P1, L1, A0) was the second child born by normal vaginal delivery with some dysmorphic features as per mothers history, and is a product of non-consanguineous marriage with no significant perinatal history and family history. ANC scans were normal. Patient was operated for circumcision and for bilateral herniotomy at six years of age. Child has delayed mile stones in the form of global developmental delay with scholar he backwardness.

\section{On Examination}

General condition was unstable, afebrile, hydration normal. Vitals are- Heart Rate-144bpm, Respiratory Rate- 30, Normal Peripheral Pulses, BP-110/70mmHg. Length $-163 \mathrm{~cm}$, US$65 \mathrm{~cm}, \mathrm{LS}-98 \mathrm{~cm}$, Arm span $-143 \mathrm{~cm}, \mathrm{HC}-53 \mathrm{~cm}, \mathrm{CC}-87 \mathrm{~cm}$. Us: $L s=0.8 \mathrm{~cm}$, length of a finger as long as $10.5 \mathrm{~cm}$.

\section{Systemic Examination}

Respiratory system is bilaterally asymmetrical in the form of significant anterior protuberance of sternal area referring to Pectus Carinatum chest. He has signs of respiratory distress. Resonant note present on right side with dull note node found all over left side on the chest. On auscultation signs were suggestive of wide spread pneumonitis.

Financial or Other, Competing Interest: None.

Submission 23-11-2015, Peer Review 04-12-2015,

Acceptance 10-12-2015, Published 03-03-2016.

Corresponding Author:

Dr. Priyanka Karande,

34, IHR, Resident Hostel,

Krishna Institute of Medical College and Hospital,

Malkapur, Karad-415110.

E-mail: priyankakarande5@gmail.com

DOI: $10.14260 /$ jemds/2016/212
Cardiac status was normal.

CNS: Conscious, oriented.

P/A: Flat abdomen with two surgical marks of herniotomy.

Special examination revealed bilateral massive exophthalmos, patient has a refractive error (Myopia). Triangular forehead, hypertelorism and low set of ears, Arachnodactyly in all digits with clubbing, long limbs, Pectuscarinatum, severe scoliosis and high arched palate. He has hypoplastic mandible with fish mouth with dysarthria.

Skeletal annerule revealed unduly tall height with tall slender fingers and toe with bilateral CTEV. Keel pectus carinatum, extreme scoliosis, varus deformity both feet.

\section{Investigations}

CBC shows normal hemogram with reduced TLC, routine electrolytes, RFT, LFT were normal. TFT shows slight on lower side TSH. Karyotype reports are awaited.

\section{X-Ray of Skull}

Deformity with mild craniofacial disproportion. Vault shows heterogeneous ossification, Lacunar skull, Synostosis.

\section{X-Ray of Chest}

Lung shows bilateral pneumonitis, Cardiac shadow cannot be commented upon due to overlapping thoracic deformity.

\section{X-Ray of Spine}

Showed left vertebral body is anteriorly beaking, widening of spinal canal in the lumbar region and grade IV spondylolisthesis of L5 over S1; has Kyphoscoliotic deformity with dysplastic vertebra in thoracic vertebra. Disc appeared to be normal.

\section{X-Ray of Upper Extremities}

Delayed skeletal maturity noted, Long bones appear slender osteopenic, Wrist joint shows subluxation, Bone age around 4 years. Ultrasound examination of abdomen revealed normal study.

\section{CT Thorax (Plain and HRCT)}

Deformed bony thoracic cage, Pleural thickening along posterior costal margin (R>L), Ground glass opacity with interlobular septal thickening and area of consolidation involving bilateral lung fields features likely s/o Acute Respiratory Distress Syndrome. 


\section{DISCUSSION}

A common feature in people with Shprintzen Goldberg Syndrome is Craniosynostosis. This early fusion preventing skull growth also shows facial dysmorphism including a long narrow head, Hypertelorism, bilateral Exophthalmos, antimongoloid slant of a palpebral fissure, a high arched palate, severe mandibular hypoplasia and narrow maxilla, low set ears. These characteristics were also present in the patient described in this study. 3,4

Children with Shprintzen Goldberg Syndrome are often said to have a marfanoid habitus, because their bodies resemble those of people with a genetic condition called Marfan syndrome. They may have Arachnodactyly, usually long limbs, Pectus-Excavatum or Pectus-Carinatum and Scoliosis. And can have Camptodactyly, Hypermobility of ligaments and tendons. It should be stressed that in contrast to Marfan syndrome, which is characterised by enophthalmos, Shprintzen-Goldberg syndrome is characterised by proptotic eyes because of the existing craniosynostosis. ${ }^{3,4}$ Children with Shprintzen-Goldberg Syndrome often have delayed development and mild-to-moderate intellectual disability. ${ }^{4}$

Shprintzen-Goldberg Syndrome has signs and symptoms similar to those of Marfan syndrome and another genetic condition called Loeys-Dietz Syndrome. However, intellectual disability is more likely to occur in Shprintzen-Goldberg Syndrome than in other two conditions. In addition cardiac abnormalities are more common and more severe in Marfan syndrome and in Loeys-Dietz Syndrome. ${ }^{4}$

Anterior facial height is increased suggesting a dolichofacial growth type with weak muscular system. Mandibular growth direction follows the dolichofacial type with posterior mandibular rotation. The increased vertical facial dimension is attributed to the counteracting mechanism of the sagittal synostosis of the cerebral cranium and the anterior cerebral fossa leading to a total craniofasiostenosis. ${ }^{5}$

\section{Genetic Information}

Shprintzen-Goldberg Syndrome is autosomal dominant and often caused by mutations in the SKI gene.

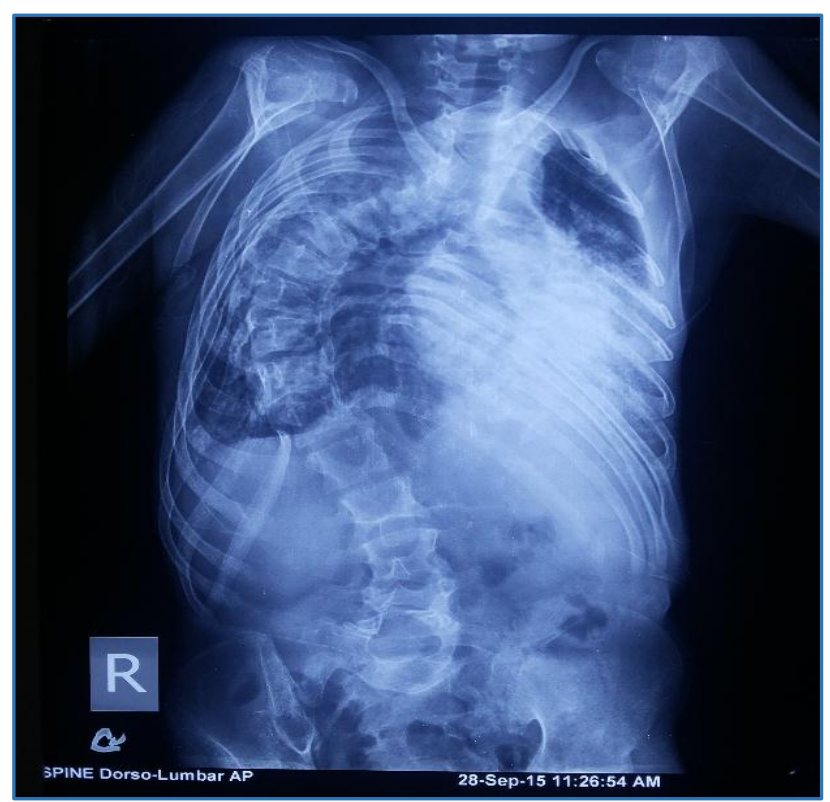

Fig. 1: Showing Kyphoscoliotic deformity with dysplastic vertebra in thoracic vertebra

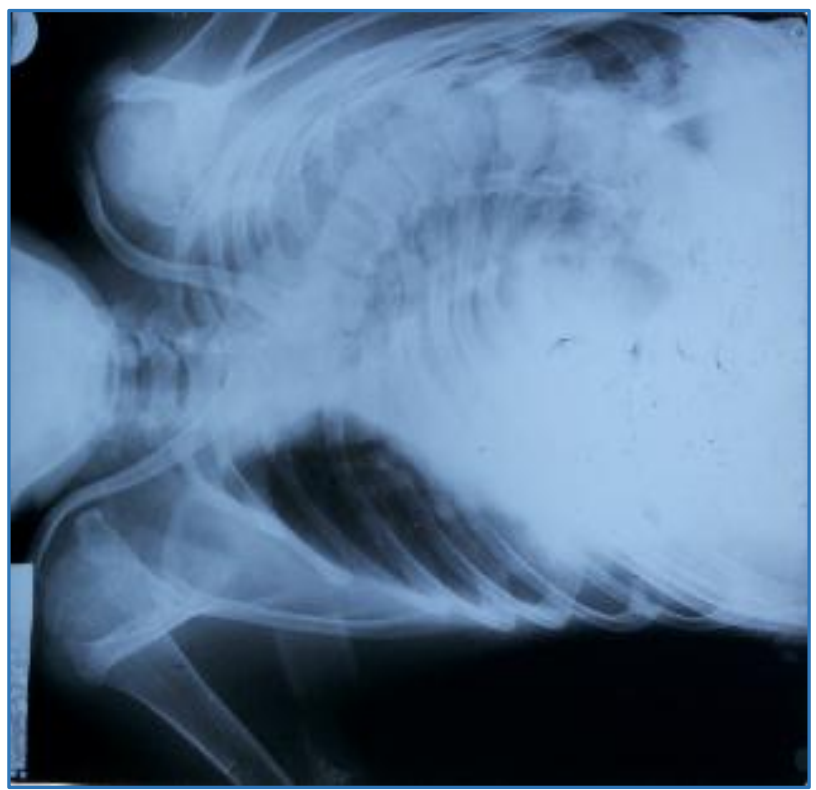

Fig. 2: Showing Kyphoscoliotic deformity with dysplastic vertebra in thoracic vertebra

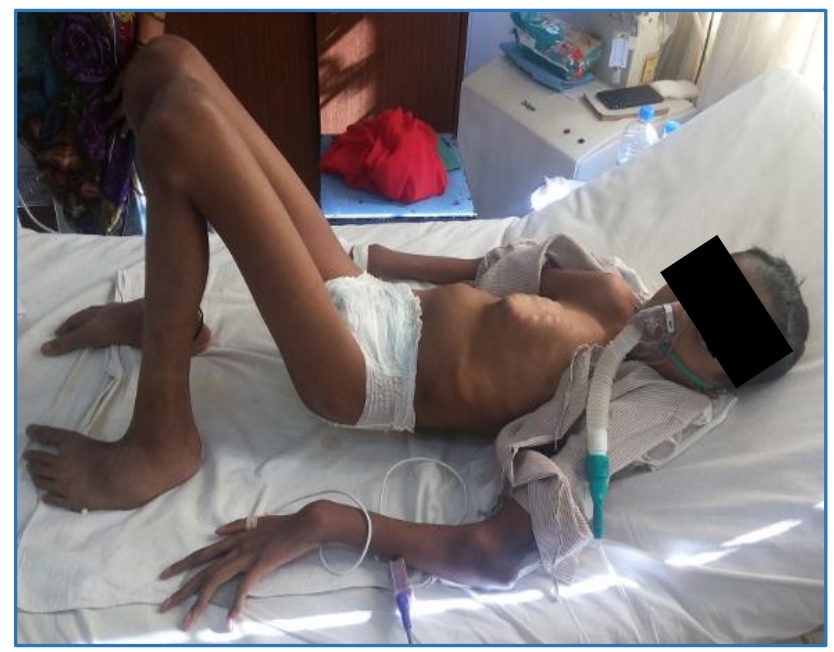

Fig 3: Showing delayed skeletal maturity noted, Long bones appear slender osteopenic, Showing PectusExcavatumor Pectus-Carinatum, Triangular forehead, hypertelorism, and low set of ears.

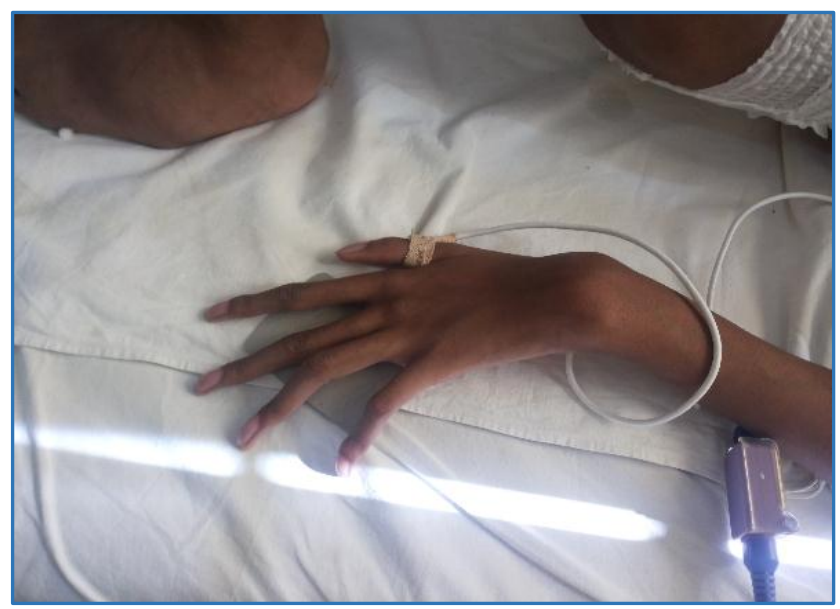

Fig. 4 Wrist joint shows subluxation, Bone age around 4 year, Arachnodactyly, clubbing of nails. 


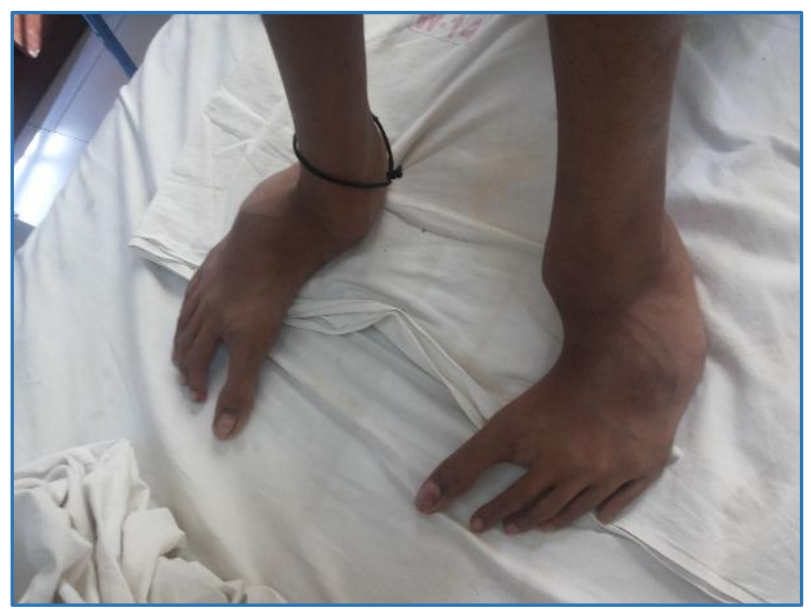

Fig. 5: Long and slender toes, with deformed foot.

\section{REFERENCES}

1. Cohen MM Jr. Craniosynostosis and syndromes with Craniosynostosis: incidence, genetics, penetrance, variability and new syndrome updating. In O'Donnell JJ, Hall BD, ed. Penetrance and variability in malformation syndromes. New York: Alan R Liss, Inc. for the National Foundation-March of Dimes. BD: OAS1979;XV(5B):13-63.

2. Cohen MM Jr. Craniosynostosis update. Am J Med Genet 1988;4 (Suppl):99-148.

3. Gorlin RJ, Cohen MM, Hennekam R. Syndromes of the head and neck. $4^{\text {th }}$ ed. New York: Oxford; 2001;696-703.

4. http://ghr.nlm.nih.gov/condition/ Shprintzen-GoldbergSyndrome.

5. Langlade M. Diagnostic orthodontique. Paris; Maloine SA; $1981 ; 175-256$. 